\title{
Various ages of recycled material in the source of Cenozoic basalts in Southeast China: Implications for the role of the Hainan plume
}

\author{
YAN-QING LI ${ }^{1,2^{*}}$, HIROSHI KITAGAWA ${ }^{2}$, EIZO
} NAKAMURA $^{2}$ AND XIANGYUN HU ${ }^{1}$

${ }^{1}$ Institute of Geophysics \& Geomatics, China University of Geosciences, Wuhan 430074, China

(*correspondence: yanqingli@okayama-u.ac.jp )

${ }^{2}$ Pheasant Memorial Laboratory, Institute for Planetary

Materials, Okayama University at Misasa, 682-0193, Misasa, Tottori, Japan

Subduction processes introduce crustal materials into the mantle, while mantle plumes return them back to the surface. However, when and how the subducted materials were recorded in the plume-related basalts remains unclear. Cenozoic basalts are widely distributed in Southeast Asia close to the west Pacific subduction zone and the seismically detected "Hainan Plume". Volcanism beginning in the late Oligocene in the continental margin of SE China consistently becomes young landward. Together with the synchronous basalts from the South China Sea and the Indochina peninsula, the volcanoes close to the Pacific subduction zone exhibit more radiogenic $\mathrm{Pb}$ and $\mathrm{Sr}$ isotopes associated with less radiogenic $\mathrm{Nd}$ isotopes compared to those of the inland volcanoes. Such spatiotemporal variations in radiogenic isotopes imply oceanic crusts of different ages in the source, each corresponding to a different geographical volcanic belt. Specific major-trace element signatures reveal the important roles of recycled oceanic crust along with surface sediment, that was inconsistently dehydrated during subduction. A geologically, geochemically, and geographysically plausible scenario is proposed to illustrate the time-space-source correation of the late Cenozoic basaltic lavas in SE Asia. The Hainan plume delivered the ancient subducted crust (1.5 Ga) from the core-mantle boundary and, subsequently, the subducted Pacific plate crustal materials from the mantle transition zone to the shallow mantle as a result of mantle convection induced by continuous subduction of the Pacific plate. Such recycled materials of different ages contributed to the geographic compositional heterogeneities of the late Cenozoic basaltic lavas in SE Asia. 